\title{
A cultura e a arte e seus múltiplos olhares na escola
}

\section{Culture and art and its multiple looks at school}

\author{
Elaine Simões Romual Rebeca*, Andrey Felipe Cé Soares** \\ * Universidade do Minho, ** Faculdade Sinergia Brasil
}

\begin{abstract}
Resumo
Pensar em cultura e arte no contexto escolar nos leva a refletir sobre as diferentes e múltiplas possibilidades de perceber seus encontros e desencontros. O objetivo desta pesquisa foi propor pensar nos movimentos entre a cultura e a arte e seu importante papel na escola. A metodologia limitou-se em pesquisa bibliográfica, análise documental e interpretativa. A pesquisa permitiu compreender a arte como um meio de potencializar a "vida" cultural da escola pelo viés artístico desencadeador de afectos e perceptos. Palavras chave: cultura, arte, escola.
\end{abstract}

\begin{abstract}
Thinking about culture and art in the school context leads us to reflect on the different and multiple possibilities of perceiving their encounters and disagreements. The purpose of this research was to propose a reflection on the movements between culture and art and its important role in school. The methodology was limited in bibliographical research, documentary and interpretative analysis. The research allowed to understand the art as a means to potentialize the cultural "life" of the school by the artistic bias triggering affects and percepts.

Keywords: culture, art, school
\end{abstract}

\section{Introdução}

Tem duas formas, ou modos, o que chamamos cultura. Não é a cultura senão o aperfeiçoamento subjetivo da vida. Esse aperfeiçoamento é direto ou indireto; ao primeiro se chama arte, ciência ao segundo. Pela arte nos aperfeiçoamos a nós; pela ciência aperfeiçoamos em nós o nosso conceito, ou ilusão, do mundo." (Pessoa, 1980)

Fernando Pessoa nas palavras acima se refere a cultura como o aperfeiçoamento subjetivo da vida, pois depende das vivências culturais de cada pessoa. Ele ainda complementa que é pela arte que nos aperfeiçoamos e pelas teorias e experiências que aperfeiçoamos o nosso conceito de mundo. Estas palavras vêm bem a calhar com o objetivo desta pesquisa que é o de propor pensar nos movimentos entre a cultura e a arte e seu importante papel na escola.

O tema "Múltiplos olhares sobre a cultura e a arte na escola", se deu pela reflexão sobre como podemos ter estes diversos olhares sobre a arte e a cultura, especificamente no contexto escolar onde ambos ainda são vistos de forma fragmentada ou apenas como uma estratégia de divulgar datas comemorativas ou abordar temas transversais.
Mas,qual o papel da cultura e da arte na formação dos indivíduos? Pois, se estamos falando de escola, estamos nos referindo a formação de sujeitos. E como já apontou Pessoa (1980) cultura e arte estão interligados neste processo de formação e de conhecimento de mundo e de sociedade em que o sujeito está inserido. Conhecer, costumes e modos de ser e estar de uma comunidade implica estarmos nela e ir em busca desta compreensão. Muitas vezes esta busca se dá pelas experiências do dia a dia, que pode levar a pesquisa e consequentemente ao conhecimento dos costumes e tradições de um determinado grupo ou sociedade de pessoas. Esta compreensão pode acontecer de maneira individual ou em grupo, acontecendo a troca e a aquisição ou incorporação de novos saberes.

A escola e o seu entorno pode ser um dos contextos destas trocas, por meio das linguagens artísticas e manifestações culturais, mediante estratégias diferenciadas, alunos, professores, pais, gestores, afinal toda a comunidade escolar podem então vivenciar experiências inovadoras potencializando assim os processos de ensino e aprendizagem. Arte e cultura neste ínterim podem resgatar histórias de vida e valores, despertando nos alunos suas potencialidades, possibilitando a expressão livre do pensamento e das emoções, desenvolvendo seu intelecto com criatividade e imaginação por meio de atividades que possam intervir em sua realidade.

Pensar em cultura e a arte no contexto escolar nos leva também a refletir sobre as diferentes e múltiplas possibilidades de perceber seus encontros e desencontros. Nesta junção de cultura e arte podemos compreender que a cultura é marcada pelas escolhas individuais de cada ser e pelas coletivas de cada grupo. Seja na família, na igreja, na escola ou em grupo de amigos, o que se vivencia em sociedade contribui diretamente na constituição do perfil cultural do sujeito.

Já quanto a arte a percebemos como algo que envolve o emocional, provoca, incomoda e gera pensares. $\mathrm{Na}$ arte, encontramos pequenos, mas grandiosos em significado, fragmentos de um sujeito que não tem a intenção de comunicar ou tampouco influenciar com suas ideias, mas que busca representar, expressar seus pensares e sentimentos, seu ideal para si mesmo; busca socializar, externalizar para o mundo o que vem refletindo a respeito do que vive. 
$\mathrm{Na}$ busca desta reflexão sobre cultura e arte no contexto escolar, este texto nos convida a devanear sobre estes possíveis encontros. Propomos pensar nos movimentos entre a cultura e a arte e seu importante papel na escola. Sugere-se que a fomentação da arte e da cultura no contexto escolar seja espontânea, envolvente e convidativa. Pretende-se compreender a cultura e a arte como uma possibilidade à sensibilização dos alunos.

Seguindo esta linha de pensamento, a escola pode ser vista como um espaço educacional que possui potência para constituir-se em um espaço cultural, que se encontra em constante movimento, que vive e prepara para a vida, que possibilita a internalização de vários conceitos, que envolve a comunidade escolar na formação humana, integral e social. Entretanto, será que essa escola reconhece suas possibilidades de auto- potencialização?

Uma proposta seria reconhecer na escola um lugar para as diferentes manifestações artísticas que compõem um movimento cultural que, por sua vez, privilegia a formação estésica e a mediação cultural entre (por) todos os sujeitos. Seria um movimento de e para a cultura? Ou seria isso Arte? Como pode a arte - a cultura - nos provocar a pensar e a viver?

A arte, portanto, pode ser vista neste texto como um meio de potencializar a "vida" cultural da escola pelo viés artístico desencadeador de afectos e perceptos. Preconiza-se assim que a cultura e a arte na escola poderiam nortear os olhares e os pensares e até o reconhecimento de que existem encontros, agenciamentos e forças culturais que desencadeiam muitas outras histórias. Diante do exposto, escritos, estudos, pesquisas e achados de alguns autores foram analisados: Deleuze, Guattari, Nietzsche, Cuche, Coelho, Nogueira e Soares, os quais tratam do tema em questão, nos levando a uma conceptualização sobre a cultura e a arte e seus múltiplos olhares na escola.

\section{Afinal o que é cultura e arte?}

Cultura é um termo polissêmico, aberto a várias interpretações. Por isso, possibilita entendimentos diversos, às vezes paralelos, outras vezes contraditórios. (Nogueira, 2008, p. 22)

Conforme aponta Nogueira na epigrafe tanto o termo como o conceito de cultura são múltiplos, o termo se origina do latim cultur e seu significado está relacionado ao cultivar, assim como ao conceito de cultivo do espírito. No entanto, quando falamos em cultura, referimo-nos "[...] unicamente a todo movimento social que se aplica aos seres humanos" (Cuche, 2002, p. 13).Mesmo que tratemos de objetos, manifestações artísticas, movimentos ideológicos, políticos ou econômicos, o resultado sempre envolverá o humano.

Por isso, com o passar dos tempos, após uma evolução gradativa do termo, cultura passa a ser associada à "formação" dos homens e ao estado de espírito cultivado pela instrução, ou seja, aquele que se destaca na sociedade em decorrência de seus conhecimentos científicos e artísticos. Para Nogueira (2008, p. 23), “[...] cultura é um termo que se torna emblemático do pensamento iluminista, associado sempre às ideias de progresso, educação e razão".
Assim, quando pensamos em cultura, dentre tantos significados, podemos também relacionar a modos de vida, diferentes pensamentos, escolhas e sentidos, pois, para a humanidade, nada é puramente natural, tudo é resultado de escolhas de um grupo, dentro de um coletivo em relação a outros grupos. Segundo Cuche, "Toda cultura é um processo permanente de construção, desconstrução e reconstrução. $O$ que varia é a importância de cada fase, segundo as situações". (2002, p. 137)

Com base nessa múltipla possibilidade de ler a realidade e as interações, a cultura começa a ser compreendida como um sistema extremamente dinâmico e complexo, um conjunto de elementos culturais que não estão necessariamente interligados, uma vez que: "Os elementos que compõem uma cultura não são jamais integrados uns aos outros pois provém de fontes diversas no tempo e no espaço" (Cuche, 2002, p. 140). Sendo assim, podemos também compreender cultura como um movimento complexo que se "alimenta" de diferentes processos sociais, artísticos, históricos, religiosos e políticos, que não se integram, mas se inter-relacionam. $\mathrm{E}$, por vezes, acabam se integrando como decorrente desse constante movimento de construção, de desconstrução e de reconstrução, pois eles se "misturam" no indivíduo. Cuche alegou que "Talvez fosse melhor substituir a palavra 'cultura' por 'culturação' para sublinhar esta dimensão dinâmica da cultura" (2002, p. 137).

Concordando com Cuche, podendo assim chamar de CULTURAÇÃO o processo de interação social cujos elementos artísticos, históricos, religiosos, políticos e culturais contribuem para a formação do sujeito, formalizando desta forma a apropriação cultural, cujos elementos passam a constituir o perfil do sujeito.

Desta maneira cultura é vista pelos autores em questão como um movimento de formação humana, que envolve diversos elementos culturais e sociais. Pensamento que contribui para o conceito de que o ser cultural é um ser humano dedicado a cultivar o saber, a ampliar seu olhar diante da realidade e de produzir cultura por meio das múltiplas possibilidades de manifestação artística e cultural. Onde as culturas resultantes de vivências interativas podem causar um afetamento decorrente das escolhas de cada sujeito ou do disponibilizado no meio social. Concordando assim com o pensamento de Sapir (citado por Cuche 2002), quando afirma que: " $O$ verdadeiro lugar da cultura está nas interações individuais" (p. 105)

E arte, o que é? Sem delongas, para agora, podemos dizer que é um processo de humanização. Carlos Drummond de Andrade questionou, "E a arte, como a educação e tudo o mais, que fim mais alto pode ter em mira senão este, de contribuir para a educação do ser humano vida, o que, numa palavra se chama felicidade? " (1974) Sim Drummond a arte pode contribuir para a humanização dos sujeitos.

Então como pode a arte a cultura nos provocar a pensar e a viver? Uma proposta seria reconhecer na escola um lugar para as diferentes manifestações artísticas que compõem um movimento cultural que, por sua vez, privilegia a formação estésica e a mediação cultural entre 
(por) todos os sujeitos. Como aponta Coelho "A arte é uma questão de desejo, enquanto a cultura surge como resposta inevitável a uma necessidade: uma inevitabilidade”. (2008, p. 125).

No processo educativo a arte em conjunto com a cultura pode auxiliar no desenvolvimento intelectivo dos alunos, ampliando assim a possibilidade de compreensão do mundo, estabelecendo ligações com o que já sabe, construindo desta forma novos pensares $\mathrm{e}$ conhecimentos.

Diante do que expomos até agora sobre cultura e arte, será que haveria então uma discordância, uma divergência entre ambas? Ou elas podem caminhar sempre para o mesmo objetivo?

\section{Convergências e divergências entre cultura e arte}

$\mathrm{Eu}$ te digo, aquele que não conhece a verdade é simplesmente um ignorante, mas aquele que a conhece diz que é mentira, este é um criminoso. A culpa de Galileu consistiria assim, no "pecado original" da ciência moderna. (Trecho do texto de Brecht em 1945)

Galileu Galilei - “Leben des Galileu” - é uma peça teatral que esteve em cartaz no Teatro Tuca, na Pontifícia Universidade Católica de São Paulo (PUC). Com texto de Bertold Brecht, de 1945, escrito em colaboração com o ator anglo-americano Charles Laughton, a peça convidou-nos a trazer a epígrafe citada. A vida de Galileu, uma peça encenada nos palcos de teatro, cuja montagem tem como atriz principal Denise Fraga, narra parte da biografia do artista italiano que conseguiu provar que a terra girava em torno do sol. Essa obra-prima cênica representa um testamento filosófico de Brecht cujo texto, "Infeliz a terra que precisa de heróis" sintetiza os temas mais frequentes de sua obra: o problema do herói, sua discutível utilidade e o uso da razão como instrumento de luta contra a barbárie.

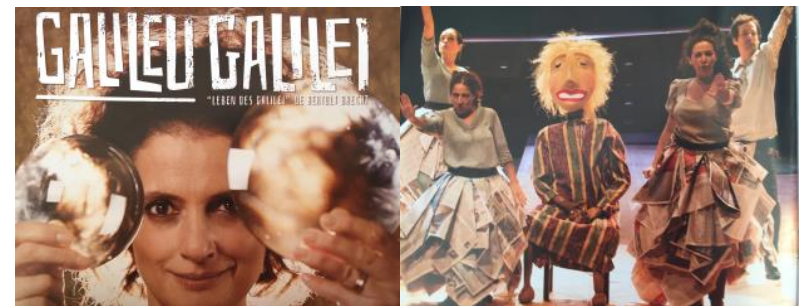

Figura 1: Galileu Galilei - Fragmentos do encarte da Peça teatral: "Leben des Galilei".

A peça teatral submete o público presente a uma formação estésica, ao refinamento dos sentidos por meio da arte, da literatura e da filosofia, ou seria à culturalização, à civilização? O espetáculo discute: Quem fora Galileu? Ele tinha razão? Luzes, cenários, um sobe e desce do palco, movimentos marcados, público compenetrado - podia-se ouvir o respirar de algumas pessoas - uma oratória impecável dos atores em cena e um texto clássico e ao mesmo tempo contemporâneo.

Seria esse movimento a cultura? Ou seria isso Arte? Deixar-nos estesiados de tanta beleza e por inúmeros estranhamentos, colocar-nos imersos nessa gama de conhecimentos e de sensações, envoltos de pensares vinculados aos sentidos aflorados pelo contato com as diferentes manifestações artísticas será papel da cultura ou cabe à arte? É.... acreditamos que seja a hora de compreendermos melhor esse território da arte e a sua relação com a cultura! Qual sua relação com o jogo ideológico, político e econômico a que estamos submetidos diariamente ?Como pode a arte - a cultura nos provocar a pensar e a viver? Permitindo-nos agenciamentos? Já afirmara Friedrich Nietzsche (1844 1900) que "[...] a arte e nada mais que arte é a grande possibilitadora da vida, a grande aliciadora da vida, o grande estimulante da vida".

Desde a Renascença, no final do século XIX, a arte tem sido visualizada por muitos como uma forma de rebeldia frente às regras de civilização e da elitização. A arte estaria associada a um olhar e a um movimento social individual e não coletivo, enquanto a cultura estaria diretamente associada ao pensar coletivo. Segundo Coelho, "A arte é vizinha da cultura, mas as aproximações entre uma e outra acabam na zona movediça que, de algum modo, delimita os territórios de uma e outra. As diferenças entre cultura e arte são mais significativas que suas semelhanças [...]” (2008, p. 117). De certo que há, de fato, convergências e divergências entre esses dois movimentos. Ao lermos o livro A cultura e seu contrário (Coelho, 2008), fomos surpreendidos por diferentes olhares conceituais. Saberes que não eram contemplados em nossos pensares! Por isso a necessidade de desvendar os múltiplos conceitos sobre a ARTE e a CULTURA - podendo até reconhecer que a cultura existe sem a arte!

No olhar do autor, na arte se destaca o pensar do sujeito, do indivíduo, do grupo que cria a obra para uma comunidade e não uma comunidade que cria ou reproduz em prol de uma necessidade. "A arte é uma questão de liberdade [...]" (Coelho, 2008, p. 125). A arte é fruto do desejo, da liberdade, por isso é ímpar, única, independente, visa primeiramente atender ao artista e depois, quem sabe, ao grupo que pode ou não apreciar a criação. A arte é subjetiva, mexe com o emocional, provoca, incomoda e gera juízos. $\mathrm{Na}$ arte, encontramos pequenos, mas grandiosos em significado, fragmentos de um sujeito que não tem a intenção de comunicar ou tampouco influenciar com suas ideias, mas que busca representar, expressar sua posição e sentimentos, seu ideal para si mesmo; busca socializar, externalizar para o mundo o que vem refletindo a respeito do que vive. Talvez, por isso, que toda obra de arte, por querer ser única, exclusiva, por vezes pode até ser considerada de risco, pode desestabilizar sentimentos, anunciar mudanças conceituais e está pautada na singularidade.

A cultura por ser coletiva não depende unicamente do indivíduo para acontecer, tampouco da arte, pois a cultura está relacionada aos movimentos históricos e sociais, e às vezes artísticos, de vários sujeitos. Ela, a cultura, tem a pretensão de comunicar conceitos ou ideologias de outrem; opera com signos e símbolos que representam uma escolha coletiva, portanto visa acomodar certos pensamentos, regras, normas no intuito de confortar. Busca trazer estabilidade, que desencadeia uma identidade, um atender a necessidade de um determinado grupo, pois tem uma oratória, um discurso 
como narrativa, como um enredo, uma apresentação, um reproduzir, um desenvolver, uma solução.

Para Coelho (2008), a cultura, por ser temporal e contextualizada historicamente, pode ser interpretada, esclarecida, já a arte é matéria prima para apreciação, deleite, investigação ou negação. A cultura pode ser construída, elaborada e constituída, duradoura, cumulativa, assegura continuidade, cultua um patrimônio; enquanto a arte mostra-se efêmera, particular, atemporal, dispensa a continuidade, não acumula, está focada no instante, na unicidade. Temos como exemplo a arte contemporânea, que, por meio de sua manifestação artística, tem a intenção de provocar, afetar, incomodar, convidar a pensar. Seja uma letra de música, uma pintura, uma performance, uma poesia ou até uma instalação artística, no momento da interação entre sujeito e objeto de arte contemporânea acontece as muitas possibilidades de afetamento, estranhamento, apreciação ou imparcialidade.

Por mais inesperada que seja, a arte contemporânea recebe essa nomenclatura pela sua particularidade de estar focada no instante, dispensa entendimento, instiga o pensar, desencadeia por vezes a fruição e estabelece interações particulares a cada sujeito. A arte foge da uniformidade, ela está no campo da diversidade, das múltiplas possibilidades de pensar, na riqueza da manifestação artística e na pluralidade de olhares. A arte tem o poder de possibilitar a ampliação de nossas capacidades cognitivas para além dos limites originalmente impostos pela natureza.

Segundo Deleuze e Guatarri (2013, p. 193), "A arte conserva, e é a única coisa no mundo que se conserva. Conserva e se conserva em si (quid juris?), embora de fato, não dure mais que seu suporte de materiais (quid facti?), pedra, tela, cor, química, etc.". O que se conserva são as sensações, que, para os autores, trata-se dos perceptos e dos afectos ${ }^{1}$.

Ainda complementando, para Deleuze e Guatarri, há três ordens de saberes: a filosofia criadora de conceitos, a arte que possibilita sensações, afetamentos e a ciência que cria conhecimentos. Há uma relação transversal entre elas na constante busca de colocar ordem no caos. A arte como criadora de sensações, de forças de imanência, de virtualidades, de acontecimentos, de singularidades e de potências culturais, cujo objetivo não está em reproduzir formas, mas em identificar forças e dar visibilidade a elas como em um processo de potencialização, de dar atenção aos pequenos detalhes que são o que de fato importa.

Nesse contexto, alguns conceitos são oriundos da filosofia, mas, segundo Deleuze e Guattari (2013), há também os que fazem parte do mundo das artes, que podemos chamar de perceptos. O artista pode ser um criador de perceptos que não significa a mesma coisa que percepções. O percepto é um conjunto de sensações e percepções complexas que vai além daquele que a sente como se fosse uma descrição de determinada situação imaginada ou vivida pelo artista e que nos permite ver o mundo de outra maneira. Não há perceptos sem afectos, por sua vez, são os devires - constantes processos de mudança atuais e não futuros - que transbordam o pensar. $\mathrm{O}$ afecto é o modo de sentir e existir que atua sobre a vida daquele que o observa.

Posto isto, uma obra de arte pode liberar os afectos, visto que a criação do artista representa um conjunto de percepções e sensações, que faz com que sentimentos se tornem afectos e aquilo que as pessoas veem se torne percepto. A função da arte é despertar o percepto das percepções, é instigar o afecto das afecções - "[...] um extrair de sensações, um puro ser de sensações" (Deleuze \& Guattari, 2013, p. 197). Um convite a ver os detalhes, as aberturas, as vibrações e os agenciamentos presentes nas relações entre os seres humanos. Os perceptos e os afectos possibilitam junto aos conceitos resistir à banalidade da vida. A arte que atua como uma resistência para suportar a trágica existência humana, um meio de resistir, colocar ordem ao caos e assim conseguir transformar a existência em uma obra de arte chamada vida. A arte, portanto, pode ser vista neste artigo como um meio de potencializar a "vida" cultural da escola pelo viés artístico desencadeador de afectos e perceptos.

\section{A cultura e arte na escola}

Será que o papel da escola, da educação escolar mudou? Sim, mudou. Se, no princípio, ela foi construída como instituição que se ocupava com a transmissão de saberes, no decorrer dos anos sua função social e política foi se delineando, e, hoje, ela é percebida como uma instituição cultural. Um espaço que pela sua organização possui meios e agentes para a promoção das diferentes culturas, em especial o contato com a cultura artística, que pode possibilitar o despertar dos afectos e dos perceptos, e um refinamento dos sentidos. Trata-se de uma escola com o olhar pautado na valorização das manifestações culturais, da formação estésica, do diálogo sobre a arte, do estabelecimento de interações sociais, do incentivo para a vivência cultural artística, do reconhecimento de valores e da prática de gerar significados que permitam um aprendizado individual e coletivo.

O sensível está relacionado à apreciação da cultura, à valorização do entorno e à vivência com ele; ou seja, está relacionado às artes, ao meio ambiente, às relações intrapessoais, aos momentos familiares, à literatura desinteressada. Assim, refinar o sensível decorre de nossas experiências culturais, permitindo-nos alterar nosso estado humano embrutecido para um estado humano culturalmente refinado - fruto de uma formação estésica.

Ao vivenciarmos momentos que fomentam a formação estésica, possibilitamos o desenvolvimento de habilidades e de conhecimentos diretamente ligados ao processo de humanização. A educação estésica influencia na mudança do perfil dos sujeitos que, gradativamente, passam a perceber o ser humano com outro olhar, de respeito, de crença na capacidade individual e profissional; um olhar dentro de uma perspectiva mais humanística, de um ser capaz de aprender e apreender (Vasconcellos, 2009).

Ir além do primeiro olhar proporciona-nos processos de humanização por meio do refinamento dos sentidos, ou seja, por meio do desenvolvimento do saber sensível. 
Duarte Jr. (2001) já sinalizou, em seus escritos, que pela junção do inteligível (conhecer) ao sensível (saber) podemos desenvolver o saber estésico, um saber que aprimora o olhar, as emoções, as sensações e a forma de ver o mundo e os sujeitos.

O desenvolvimento do pensamento é fruto de uma construção sócio histórica que conta com uma diversidade de vivências ligadas ao sensível e ao cognoscível, à vida, às artes e a tudo que nela há de observar-se, interagir e perceber. Razão e sensibilidade atuam em parceria, sem superposição de uma sob outra. Essa relação contribui para a liberdade do pensamento e do conhecimento. E de que forma podemos então potencializar os processos de ensino e aprendizagem por meio da integração da cultura e da arte na escola? Acreditamos que possa ser com práticas criativas, incentivando a vivência da diversidade cultural local por meio de parcerias entre a escola, artistas e entidades culturais.

\section{Tecendo considerações...}

Destacamos que arte e cultura, apesar de suas divergências, apresentam também convergências. É, nesse caso, acreditar que, para ambas - ARTE e CULTURA - o que está em jogo não são as verdades absolutas, mas a multiplicidade de olhares, de fazeres e de movimentos artísticos e culturais. Uma cultura que pode ser artística quando se dedica a olhar o mundo e fazer o mundo a sua maneira. Uma parceria entre as diferentes linguagens artísticas e as múltiplas facetas culturais. Uma arte que pode nos remeter a um movimento cultural, que, por meio da sua transversalidade com a filosofia e a ciência, pode despertar no homem novos pensares, ampliar o olhar e refinar os sentidos cada vez que provoca sensações.

Neste estudo, definimos a cultura como um constante movimento complexo de construção, de desconstrução e de reconstrução, pautado nas interações individuais e que, por meio das diferentes manifestações artísticas e culturais, pode ser criadora de sensações, afetamentos e agenciamentos. A arte como um conjunto de movimentos que pode provocar sensações, afetamentos, estranhamentos, conexões e aproximações entre o objeto de arte e o ser humano em uma contínua relação entre os afectos e os perceptos.

Propomos pensar que ambas, a cultura e a arte, possuem importante papel na escola, desde que estes movimentos culturais sejam de promoção da cultura artística e não da cultura de civilização. Que a fomentação da arte seja natural, envolvente e convidativa e não limitadora de pensamentos. A arte que supera a função instrumental e que possibilita a sensibilização, a culturalização voltada à apreciação e à criação artística. A ideia de reconhecer na escola um lugar para as diferentes manifestações artísticas que compõem um movimento cultural que, por sua vez, privilegia a formação estésica e a mediação cultural.

A escola vista como um espaço educacional que possui potência para constituir-se um espaço cultural, que se encontra em constante movimento, que prepara para a vida, que possibilita a internalização de vários conceitos, que envolve a comunidade escolar na formação humana, integral e social. Como aponta Nogueira, "O fundamental é que a escola estimule e desenvolva todo o potencial humano, que aponte para uma efetiva formação integral [...]”' (2008, p. 140).

Propomos pensar que ambas possuem importante papel na escola, desde que os movimentos culturais sejam de promoção da cultura artística e não da cultura de civilização.

\section{Referências}

Andrade, C. D. (20 de 07 de 1974). A EDUCAÇÃO DO SER POÉTICO, por Carlos Drummond de Andrade. Acesso em 18 de 06 de 2017, disponível em ContiOutra:

http://www.contioutra.com/a-educacao-do-ser-poetico -por-carlos-drummond-de-andrade/

Coelho, T. (2008). A cultura e seu contrário: cultura, arte e política pós-2001. São Paulo: Iluminuras:Itaú Cultural.

Cuche, D. (2002). A noção de cultura nas ciências sociais. Bauru-SP: Edusc.

Deleuze, G., \& Guattari, F. (2013). Mil Platôs:Capitalismo e Esquizofrenia (Vol. 2). (A. L. Oliveira, A. G. Neto, \& C. P. Costa, Trads.) São Paulo, SP, BR.

Deleuze, G., \& Guattari, F. (2013). O que é filosofia? (Vol. 3). (B. P. Jr., \& A. A. Muñoz, Trads.) São Paulo, $\mathrm{SP}, \mathrm{BR}$.

Gauthier, C., \& Mellouki, M. H. (01 de Maio/Agosto de 2004). O professor e seu mandato de mediador,herdeiro,interprete e crítico. Educação \& Sociedade, 25(87), pp. 537-571.

Nietzsche, F. (2011). Vontade de Potência. (M. F. Santos, Trad.) Petrópolis, RJ: Vozes.

Nietzsche, F. (2015). Humano, demasiado humano: um livro para espíritos livres. (P. C. Souza, Trad.) São Paulo: Companhia das Letras.

Nogueira, M. A. (2008). Formação cultural de professores ou a arte da fuga. Goiania, GO, BR: UFG.

Pessoa, F. (1980). Arquivo Pessoa. Acesso em 2017 de 2017, disponível em Multipessoa: http://arquivopessoa.net/textos/3127

Soares, A. F. (01 de 05 de 2016). A cultura e a arte na escola e outras histórias... (UNIVALI, Ed.) Itajaí, SC, BR. Fonte: http://siaibib01.univali.br/pdf/Andrey\%20Felipe\%20 Ce\%20Soares\%202016.pdf

Vasconcellos, C. S. (2009). Coordenação do Trabalho Pedagógico: Do Projeto Político Pedagógico ao Cotidiano da Sala de Aula. São Paulo: Libertad.

\footnotetext{
Notas de rodapé

${ }^{1}$ Atriz e comediante brasileira.

${ }^{1}$ Importante ressaltar que o conceito de perceptos e afectos é definido por Spinosa em sua tese que apresenta que não há diferença de natureza entre o corpo e a alma e sim, que esses dois corpos constituem juntos um único ser. Com essa afirmação ele vai contra o pensamento que valorizava essa dualidade, onde normalmente havia presente a intenção de desvalorização do corpo e o enobrecimento da alma.
} 